\title{
Progression of mild Alzheimer's disease: knowledge and prediction models required for future treatment strategies
}

\author{
Carina Wattmo*, Åsa K Wallin and Lennart Minthon
}

\begin{abstract}
Introduction: Knowledge of longitudinal progression in mild Alzheimer's disease (AD) is required for the evaluation of disease-modifying therapies. Our aim was to observe the effects of long-term cholinesterase inhibitor (ChEl) therapy in mild AD patients in a routine clinical setting.

Methods: This was a prospective, open-label, non-randomized, multicenter study of ChEl treatment (donepezil, rivastigmine or galantamine) conducted during clinical practice. The 734 mild AD patients (Mini-Mental State Examination (MMSE) score 20 to 26) were assessed at baseline and then semi-annually over three years. Outcome measures included the MMSE, Alzheimer's Disease Assessment Scale-cognitive subscale (ADAS-cog), Clinician's Interview-Based Impression of Change (CIBIC) and Instrumental Activities of Daily Living (IADL) scale.

Results: After three years of ChEl therapy, 31\% (MMSE) and 33\% (ADAS-cog) of the patients showed improved/ unchanged cognitive ability, 33\% showed improved/unchanged global performance and 14\% showed improved/ unchanged IADL capacity. Higher mean dose of ChEl and lower educational level were both predictors of more positive longitudinal cognitive and functional outcomes. Older participants and those with a better IADL score at baseline exhibited a slower rate of cognitive decline, whereas younger participants and those with higher cognitive status showed more preserved IADL ability over time. Gender and apolipoprotein E (APOE) genotype showed inconsistent results. Prediction models using the abovementioned scales are presented.

Conclusions: In naturalistic mild AD patients, a marked deterioration in IADL compared with cognitive and global long-term outcomes was observed, indicating the importance of functional assessments during the early stages of the disease. The participants' time on ChEl treatment before inclusion in studies of new therapies might affect their rate of decline and thus the comparisons of changes in scores between various studies. An increased understanding of expected disease progression in different domains and potential predictors of disease progression is essential for assessment of future therapies in AD.
\end{abstract}

\section{Introduction}

Alzheimer's disease (AD) is an insidiously progressive neurodegenerative disorder characterized by multiple cognitive deficiencies, including increasing impairment in memory, orientation, language and executive ability, as well as deterioration of functional capacity [1]. Currently, the main treatment for mild-to-moderate $\mathrm{AD}$ is acetylcholinesterase inhibitors (ChEI), which have shown positive symptomatic effects on cognition and function compared with a placebo in randomized clinical trials [2].

* Correspondence: carina.wattmo@skane.se

Clinical Memory Research Unit, Department of Clinical Sciences, Malmö,

Lund University, Malmö, Sweden
Novel 'disease-modifying' therapies attempt to block the course of $\mathrm{AD}$ in the early phase [3]. Because placebo-controlled clinical trials of more than six months duration in untreated individuals with $\mathrm{AD}$ are considered unethical, new longer studies are instead being conducted on patients who are already being treated with ChEI. Treatment strategies include various drug candidates that mainly aim to interfere with biological changes occurring in the brain during $\mathrm{AD}$, such as the formation of beta-amyloid $(A \beta)$ plaques. Hence, several research efforts, including active immunization with $A \beta$
C Biomed Central

(c) 2013 Wattmo et al.; licensee BioMed Central Ltd. This is an Open Access article distributed under the terms of the Creative
Commons Attribution License (http://creativecommons.org/licenses/by/2.0), which permits unrestricted use, distribution, and reproduction in any medium, provided the original work is properly cited. 
and passive immunization with humanized monoclonal anti-A $\beta$ antibodies, are targeted towards preventing $A \beta$ deposition. One study, in which AD patients were actively immunized with $A \beta_{42}$, reported clearance of amyloid plaques but no improvement in time to severe dementia or survival [4]. One explanation may be that immunotherapy is effective only in the mild stages of AD. Using pooled data from the two phase 3 passive immunization trials of solanezumab, the analyses demonstrated a significant slowing of cognitive decline and a trend towards slower deterioration in instrumental activities of daily living (IADL) after 80 weeks among individuals with mild but not moderate AD [5]. Furthermore, a six-month randomized trial of mild AD patients showed that souvenaid, a medical food product containing precursors and other specific nutrients required to enhance synapse formation, significantly increased memory performance in comparison with a placebo [6].

The majority of previous long-term extensions of clinical trials [7-9] and naturalistic studies of ChEI treatment in $\mathrm{AD}[10,11]$ have enrolled participants in both mild and moderate stages; hence, for this combined cohort, the cognitive, global and functional disease progression are well described. Few longitudinal studies have reported on progression in different domains exclusively in mild AD patients. This knowledge is essential to compare the trajectories of those who have received a new therapy in addition to ChEI with those of patients treated only with ChEI, especially since therapies that may modify disease progression in $\mathrm{AD}$ require thorough long-term evaluation.

In some clinical trials of immunotherapy, the treatment arms were stratified into presence/absence of the genetic risk factor apolipoprotein E (APOE) $\varepsilon 4$ allele. Exploratory data analyses from the humanized monoclonal anti- $\mathrm{A} \beta$ antibody bapineuzumab trial observed that non-carriers of the APOE $\varepsilon 4$ allele responded better cognitively than carriers [12]. Studies have shown contradicting results regarding the impact of the $\varepsilon 4$ allele on cognitive response to ChEI treatment $[13,14]$. Possible predictors of disease progression and empirical models of the expected rate of change in cognition and IADL have not been analyzed exclusively in mild $\mathrm{AD}$ patients.

The aims of this study were to describe cognitive, global and functional longitudinal progression in mild AD, to identify the socio-demographic and clinical factors, such as APOE genotype that influence these outcomes, and to build prediction models based on data at the start of ChEI treatment.

\section{Methods}

\section{Study and subjects}

The Swedish Alzheimer Treatment Study (SATS) was undertaken to assess the longitudinal effectiveness of ChEI treatment (donepezil, rivastigmine or galantamine) over three years in AD patients in clinical practice. SATS is a prospective, open-label, observational, non-randomized, multicenter study that was reported at length in an earlier publication [10]. In total, 1,258 patients with predominantly mild-to-moderate $\mathrm{AD}$ were enrolled from 14 participating memory clinics across Sweden up until April 2008. Of these, all 734 individuals in the mild stage, that is, those participants with baseline Mini-Mental State Examination (MMSE) [15] scores ranging from 20 to 26 , were included in the present analyses.

Outpatients aged 40 years and over who received a clinical diagnosis of dementia as defined by the Diagnostic and Statistical Manual of Mental Disorders, $4^{\text {th }}$ edition (DSMIV) [16] and had possible or probable $\mathrm{AD}$ according to the criteria of the National Institute of Neurological and Communicative Disorders and Stroke and the Alzheimer's Disease and Related Disorders Association (NINCDSADRDA) [17] were considered for inclusion in SATS. Further inclusion criteria were that the participants had a knowledgeable caregiver, were living at home at the time of diagnosis and were assessable with MMSE at the start of ChEI treatment (baseline). Patients who did not fulfill the diagnostic criteria for $\mathrm{AD}$, those already receiving active ChEI treatment or individuals with contraindications to ChEI were excluded from the study. Concomitant medications other than ChEIs were documented at baseline and permitted during the study, with the exception of memantine.

All patients and/or caregivers gave their written informed consent to participate in SATS, which was conducted according to the provisions of the Helsinki Declaration and was approved by the Ethics Committee of Lund University, Lund, Sweden.

The patients were evaluated in a well-structured follow-up program, which assessed cognition, global performance and functional capacity at the start of $\mathrm{ChEI}$ treatment, after two months (MMSE and global rating only), and semi-annually for a period of three years. After recruitment in SATS and evaluation at baseline, patients were prescribed ChEI according to the approved product recommendations. The choice of treatment (donepezil, rivastigmine or galantamine) was left entirely to the physician's discretion and professional judgment. The ChEI dose was recorded after two months of treatment, and every six months after baseline assessment. Trained dementia nurses assessed the functional capacity of participants through caregiver interviews.

\section{Outcome measures}

Cognitive ability was assessed using the MMSE scale, with a range from 0 to 30 , in which a lower score indicates more impaired cognition, and using the Alzheimer's 
Disease Assessment Scale-cognitive subscale (ADAS-cog) (0 to 70 points) [18], in which a lower score indicates better cognition. The Clinician Interview-Based Impression of Change (CIBIC) [19] was used as a global measure of 'change from baseline'.

Ability to perform daily activities was assessed using the IADL scale [20] that consists of the following eight items: ability to i) use the telephone, ii) go shopping, iii) prepare food, iv) undertake housekeeping activities, v) do laundry, vi) travel independently, vii) be responsible for own medications and viii) handle finances. Each item was scored from 1 (no impairment) to 3 to 5 (severe impairment), allowing a total range of 8 to 31 points. Some of the instrumental tasks might be gender-dependent among the older generation. Therefore, a mathematical correction of the sum of the IADL scores was performed, to prevent those tasks from affecting the results. The formula used the data from the rated items to estimate a total score within the range of the total IADL scale [21].

For each assessment, mean MMSE, ADAS-cog and IADL changes from baseline with 95\% confidence intervals (CI) were calculated. To facilitate comparisons among these scales, changes in the scores calculated as positive values should be interpreted as indicating improvement and those calculated as negative values interpreted as indicating decline. Percentages of improved/unchanged patients, pre-defined as those who showed an improvement or no change ( $\geq 0$ points difference) at the respective assessment, were also calculated for the MMSE, ADAS-cog and IADL scales. The assessments of change in global performance from the start of ChEI treatment were made at all intervals using a 7- point scale that varies from 1 (very much improved) to 7 (marked worsening), with 4 indicating no change. No guidelines or descriptors were provided to define the individual ratings. The classification between, for example, minimally improved or very much improved was left to the physician's clinical judgment. In Figure 1, the patients who could not perform an individual IADL task independently (IADL score 2 to 5 ) were categorized as 'need assistance'.

\section{Statistical analyses}

The IBM Statistical Package for the Social Sciences (SPSS) software (version 21.0; IBM Corporation, Armonk, NY, USA) was used to perform statistical analyses. The level of significance was defined as $P<0.05$ if not otherwise specified. Observed-case analyses were performed to avoid overestimation of the treatment effect by imputing higher, earlier outcome scores in a longitudinal study of a progressively deteriorating disease. Parametric tests were used because of the large sample and the approximately normally distributed continuous potential predictors. A $t$ test was used to compare the differences between the means obtained for two independent groups, and a $x^{2}$ test was computed to analyze categorical variables. Pearson's correlation coefficient was calculated to investigate any linear associations between continuous variables.

Mixed, linear and non-linear fixed and random coefficient regression models [22] using the individual as a hierarchical variable (that is, to allow intra-individual correlation) were performed. In addition, the mixedeffects models take into consideration the varying number of assessment information available for each patient and unequal time intervals between follow-up visits, which are

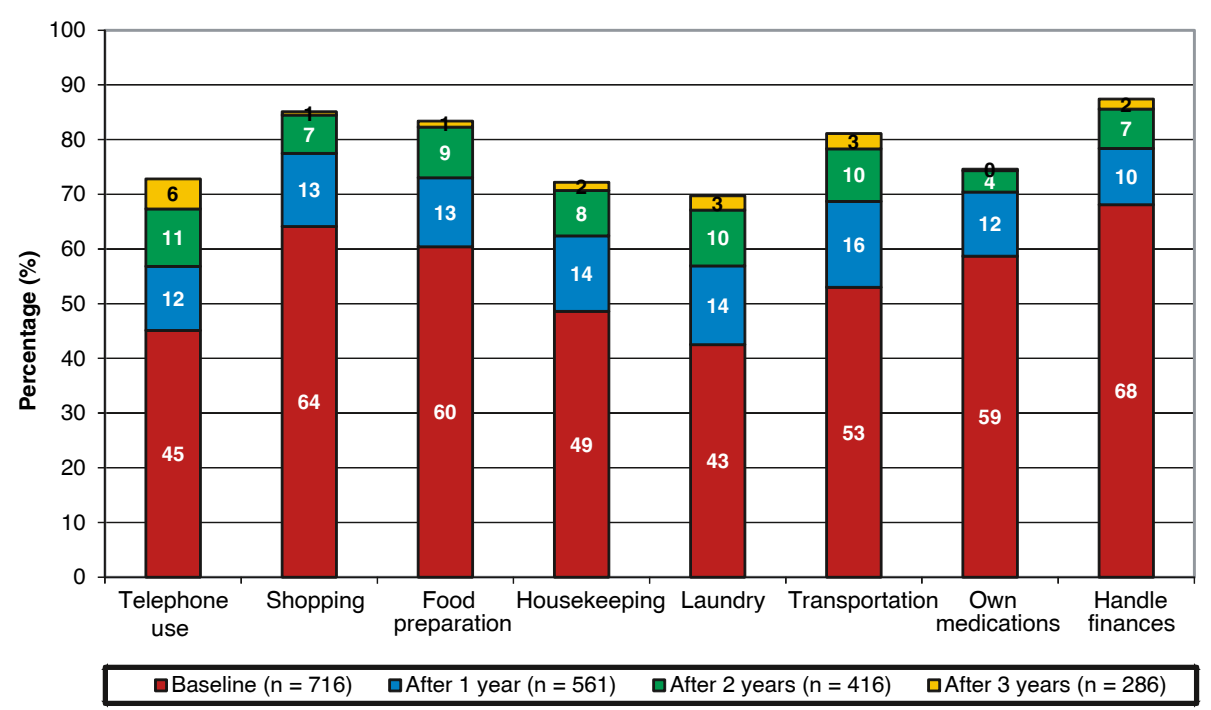

Figure 1 IADL, dependence in IADL items. Percentage of mild AD patients who are not able to perform individual IADL tasks independently (IADL score 2 to 5) at baseline and after one, two and three years of ChEl treatment. AD, Alzheimer's disease; ChEl, cholinesterase inhibitor; IADL, Instrumental Activities of Daily Living. 
common statistical limitations in long-term studies. The individuals who dropped out during the study contributed information during the time of participation; thus, we considered the trajectories of all patients.

Time was defined as the exact number of months between the start of ChEI treatment and each assessment, which indicated that all data points were used at the actual time intervals. To adjust for baseline differences, the initial cognitive or functional scores for each individual and their interaction with linear and quadratic terms for months in the study (to enable a non-linear rate of change in the models) were included as fixed effects, that is, time in months (or time in months ${ }^{2}$ ) $\times$ MMSE (ADAS-cog or IADL) baseline score. Hence, the dependent variables were the cognitive or functional scores assigned at the second and subsequent evaluations for each patient; thus, the mixed-effects models do not intend to predict the scores at the start of ChEI treatment. The random terms in the models were an intercept and time in months, with a variance components covariance matrix. Several socio-demographic and clinical characteristics were included as fixed effects. The potential predictors analyzed were classical risk factors, such as age at the start of ChEI therapy (in years), the clinician's estimate of age at onset (in years), gender, years of education, whether a carrier of the APOE $\varepsilon 4$ allele (no/yes), whether living alone (no/yes), number of medications at baseline and whether taking specific concomitant medications (no/yes for each group) including antihypertensive/cardiac therapy, anti-diabetics, lipid-lowering agents, estrogens, non-steroidal antiinflammatory drugs (NSAIDs)/acetylsalicylic acid, antidepressants, antipsychotics and anxiolytics/sedatives/ hypnotics. The effect of ChEI treatment was analyzed using different drug agents and dosages. Lastly, some biologically plausible interactions with disease severity at the start of treatment or with time in the study were included in the mixed-effects models; these were gender, education, age and APOE genotype.

The ChEI drugs were coded as a set of dummy variables. The dose could vary during the treatment period for an individual patient and between patients. For that reason, the mean dose used during the entire follow-up period was calculated for each patient. To obtain a similar metric for percentage maximum dosage for each of the three ChEI drugs, the mean dose was divided by the maximum recommended dose for each agent, that is, 10 $\mathrm{mg}$ for donepezil, $12 \mathrm{mg}$ for rivastigmine (oral therapy) and $24 \mathrm{mg}$ for galantamine. The term 'type of ChEI $\times$ dose' was also included in the models. Non-significant variables $(P>0.05)$ were removed in a backward stepwise elimination manner. The hierarchical principle was applied in these analyses; terms that appeared in interactions were not considered for elimination.

\section{Results}

Baseline characteristics

The socio-demographic and clinical characteristics of the 734 mild AD patients are shown in Table 1 . Male patients had significantly more years of education (mean \pm standard deviation (SD), $10.2 \pm 3.0$ vs $9.3 \pm 2.4$ years; $t$ $(730)=4.12 ; P<0.001)$ and a lower IADL capacity at the start of ChEI treatment $(15.4 \pm 5.1$ vs $14.3 \pm 5.0$ points; $t$ $(714)=2.94 ; P=0.003)$ compared with females. No significant differences in age, cognitive ability or number of concomitant medications at baseline were found between genders.

Individuals carrying the APOE $\varepsilon 4$ allele (69\%) were younger on average $(74.4 \pm 6.9$ vs $76.6 \pm 6.5$ years; $\mathrm{t}(716)=4.09 ; P<0.001)$, had an earlier onset of AD $(71.4 \pm 7.2$ vs $73.9 \pm 6.7$ years; $\mathrm{t}(713)=4.50 ; P<0.001)$ and had a higher IADL capacity at baseline (14.3 \pm 5.1 vs $15.3 \pm 4.9$ points; $\mathrm{t}(698)=2.57 ; P=0.010)$ compared with non-carriers. No differences in years of education, cognitive ability or number of concomitant medications at the start of ChEI treatment were detected between carriers and non-carriers of the APOE $\varepsilon 4$ allele.

\begin{tabular}{lc} 
Table $\mathbf{1}$ Socio-demographic and clinical characteristics \\
( $\boldsymbol{n}=\mathbf{7 3 4 )}$ \\
\hline Variable & \\
\hline Female gender & $473(64 \%)$ \\
APOE $\varepsilon 4$ carrier, ( $n=718)$ & $493(69 \%)$ \\
Solitary living at baseline & $267(36 \%)$ \\
Anti-hypertensives/Cardiac therapy & $290(40 \%)$ \\
Anti-diabetics & $38(5 \%)$ \\
Lipid-lowering agents & $94(13 \%)$ \\
Estrogens & $52(7 \%)$ \\
NSAIDs/Acetylsalicylic acid & $221(30 \%)$ \\
Anti-depressants & $183(25 \%)$ \\
Anti-psychotics & $26(4 \%)$ \\
Anxiolytics/Sedatives/Hypnotics & $111(15 \%)$ \\
Variable & Mean \pm standard \\
& deviation \\
Estimated age at onset (years) & $72.3 \pm 7.1$ \\
Estimated duration of AD at baseline (years) & $2.9 \pm 2.0$ \\
Age at first assessment (years) & $75.2 \pm 6.8$ \\
Education (years) & $9.6 \pm 2.6$ \\
MMSE score at baseline & $23.4 \pm 2.0$ \\
ADAS-cog score (0-70) at baseline & $17.5 \pm 6.7$ \\
IADL score at baseline & $14.7 \pm 5.0$ \\
Number of concomitant medications at & $2.9 \pm 2.4$ \\
baseline & \\
ADAS-cog Alzeims & \\
&
\end{tabular}

ADAS-cog, Alzheimer's Disease Assessment Scale-cognitive subscale; APOE, apolipoprotein E; IADL, Instrumental Activities of Daily Living scale; MMSE, Mini-Mental State Examination; NSAIDs, non-steroidal anti-inflammatory drugs. 
Older age at baseline was linearly associated with lower IADL capacity $(n=716, r=0.326, P<0.001)$ and greater number of concomitant medications at baseline ( $n=734, r=0.228, P<0.001)$. In addition, lower IADL capacity and more concomitant medications correlated weakly ( $n=716, r=0.194, P<0.001)$ with each other. Weak linear relationships between older age and lower level of education $(n=732, r=-0.130, P<0.001)$ or more impaired cognition (MMSE: $n=734, r=-0.097$, $P=0.008$; ADAS-cog: $n=724, r=0.181, P<0.001)$ at the start of ChEI therapy were found.

\section{Longitudinal outcomes in mild AD}

The mean MMSE, ADAS-cog and IADL actual scores and the changes from baseline scores during three years are shown in Table 2. The percentages of patients who showed improvement or remained unchanged at each visit according to these measures are also reported. In Table 3, the above-mentioned results are presented separately for APOE $\varepsilon 4$-carriers and non-carriers. The changes in global performance (CIBIC) from the start of ChEI treatment over the three-year study are illustrated in Figure 2. After one year, 23\% of the remaining SATS participants with mild AD were globally improved and $38 \%$ unchanged, after two years, the proportions were $13 \%$ and $29 \%$, respectively, and after three years, the proportions were $12 \%$ and $21 \%$. The percentage of patients who needed help to perform individual IADL items is displayed in Figure 1. At baseline, 45\% to 65\% could not perform usual IADL tasks independently, and after three years $70 \%$ to $85 \%$ of the remaining mild $\mathrm{AD}$ patients in the study needed assistance with IADLs.

\section{ChEl therapy}

Of the 734 patients, 354 (48\%) received donepezil, 162 (22\%) rivastigmine and 218 (30\%) galantamine. After one year, the mean \pm SD doses of donepezil, rivastigmine and galantamine were $7.7 \pm 2.6,7.6 \pm 2.9$ and $18.4 \pm 4.4$ $\mathrm{mg}$, respectively. After two years, they were $8.1 \pm 2.5$, $8.1 \pm 2.9$ and $19.4 \pm 4.5 \mathrm{mg}$, and after three years the doses were $8.4 \pm 2.4,8.3 \pm 2.7$ and $20.3 \pm 4.2 \mathrm{mg}$, respectively.

\section{Dropout analyses}

Overall, $58 \%$ of the mild AD patients did not complete the three-year study. The reasons for dropout from the study were admission to nursing home $(12 \%, \mathrm{n}=87)$, side effects $(8 \%, \mathrm{n}=57)$, initiation of concomitant memantine therapy $(6 \%, \mathrm{n}=42)$, compliance problems $(5 \%, \mathrm{n}=38)$, death $(5 \%, \mathrm{n}=35)$, withdrawal of informed consent $(5 \%, \mathrm{n}=35)$, switching to another study $(4 \%, \mathrm{n}=31)$, poor effect/deterioration $(4 \%, \mathrm{n}=28)$, somatic disease assumed unrelated to $\mathrm{AD}(3 \%, \mathrm{n}=19)$, switching to another ChEI agent $(2 \%$, $\mathrm{n}=15)$, and other reasons $(5 \%, \mathrm{n}=37)$.
The patients who remained in SATS for the complete three-year follow-up period exhibited significantly better cognitive (mean \pm SD; MMSE, $23.6 \pm 2.0$ vs $23.1 \pm$ 1.9 points; $\mathrm{t}(732)=3.62 ; P<0.001$; ADAS-cog, $16.1 \pm$ 6.8 vs $18.4 \pm 6.5$ points; $\mathrm{t}(722)=-4.74 ; P<0.001)$ and IADL $(13.5 \pm 4.6$ vs $15.5 \pm 5.2$ points; $\mathrm{t}(714)=-5.48 ; P<0.001)$ abilities at baseline than patients who dropped out, and received a greater percentage of the maximum recommended ChEI dose during the study ( $69 \pm 17$ vs $59 \pm 18 \%$; $\mathrm{t}(732)=$ $7.50 ; P<0.001)$. The other patient characteristics of gender, presence of the APOE $\varepsilon 4$ allele, solitary living, age at onset, age at the start of ChEI treatment, years of education, number of concomitant medications and specific medications received did not differ between the completers and those who discontinued the study.

\section{Predictors of longitudinal cognitive and functional outcomes}

In the mixed-effects models, only patients with three or more assessments $(\mathrm{n}=656,89.4 \%)$ were included, in order to enable analyses of a non-linear rate of cognitive or functional change. The models were performed $(3,280$ data points) to identify the socio-demographic and clinical factors that affected the long-term trajectories of mild $\mathrm{AD}$ patients. The percentages of variance that accounted for the dependent variable, regarding all fixed predictors, were $28.6 \%$ for MMSE, 37.6\% for ADAS-cog, and $60.9 \%$ for IADL, indicating a moderate to very good fit of the models $(P<0.001)$. The mixed-effects models, significant predictors, and unstandardized $\beta$ coefficients with $95 \% \mathrm{CI}$ are presented in Table 4. Male individuals (MMSE only), non-carriers of the APOE $\varepsilon 4$ allele (ADAS-cog only), those with more preserved IADL ability at baseline and patients receiving a higher mean dose of ChEI during the study (irrespective of drug agent) exhibited a more favorable longitudinal cognitive outcome. Individuals living with a family member, those with better cognitive status at baseline and patients receiving a higher ChEI dose showed less deterioration in IADL during the three-year study.

The interaction effects of cognitive severity, age at baseline, time in months from the start of ChEI therapy, and years of education showed that these variables cannot be interpreted separately. Older individuals with mild AD exhibited a better long-term cognitive outcome compared with younger individuals. For example, 85year-old patients with a baseline MMSE score of 23 demonstrated, on average, 2.3 points better than 65 year-old patients. Similarly, 85-year-old patients with a baseline ADAS-cog score of 18 showed an additional 6.4 points better compared with 65-year-old patients after three years of ChEI treatment. In contrast, the corresponding mean outcome in IADL score was 0.8 
Table 2 Changes in cognitive and functional abilities during three years of ChEl treatment in mild AD

\begin{tabular}{|c|c|c|c|c|c|c|c|}
\hline Variable & $\begin{array}{l}2 \text { months } \\
(n=706)\end{array}$ & $\begin{array}{l}6 \text { months } \\
(n=662)\end{array}$ & $\begin{array}{l}12 \text { months } \\
(n=597)\end{array}$ & $\begin{array}{c}18 \text { months } \\
(n=521)\end{array}$ & $\begin{array}{c}24 \text { months } \\
(n=450)\end{array}$ & $\begin{array}{l}30 \text { months } \\
(n=374)\end{array}$ & $\begin{array}{l}36 \text { months } \\
(n=306)\end{array}$ \\
\hline Completion rate (\%) & 96.2 & 90.2 & 81.3 & 71.0 & 61.3 & 51.0 & 41.7 \\
\hline MMSE score ${ }^{a}$ & $24.0(23.8,24.2)$ & $23.5(23.3,23.8)$ & $22.8(22.5,23.2)$ & $22.1(21.7,22.5)$ & $21.4(20.9,21.8)$ & $21.1(20.5,21.6)$ & $20.6(20.0,21.2)$ \\
\hline ADAS-cog (0 to 70) score ${ }^{a}$ & & $17.4(16.8,18.0)$ & $18.3(17.6,19.0)$ & $19.5(18.6,20.3)$ & $20.1(19.1,21.1)$ & $21.3(20.0,22.7)$ & $21.7(20.2,23.2)$ \\
\hline IADL score ${ }^{a}$ & & $15.8(15.4,16.2)$ & $17.0(16.6,17.5)$ & $17.9(17.4,18.5)$ & $18.8(18.2,19.4)$ & $19.4(18.7,20.1)$ & $19.8(19.1,20.6)$ \\
\hline MMSE score, change from baseline $e^{a}$ & $0.61(0.43,0.78)$ & $0.19(-0.04,0.42)$ & $-0.57(-0.86,-0.28)$ & $-1.31(-1.66,-0.96)$ & $-2.20(-2.64,-1.77)$ & $-2.54(-3.06,-2.02)$ & $-3.10(-3.66,-2.54)$ \\
\hline ADAS-cog (0 to 70) score, change from baseline ${ }^{a}$ & & $-0.15(-0.65,0.34)$ & $-1.20(-1.77,-0.63)$ & $-2.58(-3.27,-1.90)$ & $-3.81(-4.59,-3.03)$ & $-4.97(-6.09,-3.85)$ & $-6.12(-7.35,-4.89)$ \\
\hline IADL score, change from baseline ${ }^{a}$ & & $-1.12(-1.34,-0.91)$ & $-2.48(-2.78,-2.17)$ & $-3.64(-4.01,-3.26)$ & $-4.75(-5.18,-4.33)$ & $-5.54(-6.06,-5.02)$ & $-6.27(-6.86,-5.68)$ \\
\hline MMSE score, improved/unchanged patients (\%) & 72.7 & 64.1 & 55.0 & 46.9 & 41.9 & 38.2 & 33.0 \\
\hline $\begin{array}{l}\text { ADAS-cog (0 to } 70) \text { score, improved/unchanged } \\
\text { patients (\%) }\end{array}$ & & 55.3 & 48.8 & 41.8 & 36.7 & 32.9 & 31.1 \\
\hline IADL score, improved/unchanged patients (\%) & & 49.7 & 34.2 & 24.3 & 18.0 & 14.8 & 13.8 \\
\hline
\end{tabular}

${ }^{\mathrm{a} M e a n}$ (95\% confidence interval).

For clarity, clinical improvements for all scales have been tabulated as positive changes from the start of ChEl treatment (baseline).

ADAS-cog, Alzheimer's Disease Assessment Scale-cognitive subscale; ChEl, cholinesterase inhibitor; IADL, Instrumental Activities of Daily Living scale; MMSE, Mini-Mental State Examination. 
Table 3 Changes in scores during three years of ChEl treatment in mild AD by APOE genotype

\begin{tabular}{|c|c|c|c|c|c|c|c|c|c|}
\hline \multirow[b]{2}{*}{ Number of non-carriers/ $\_4$-carriers ${ }^{b}$} & \multicolumn{3}{|c|}{ MMSE score $^{a}$} & \multicolumn{3}{|c|}{ MMSE score, change from baseline ${ }^{a}$} & \multicolumn{3}{|c|}{ MMSE score, improved/unchanged patients (\%) } \\
\hline & Non-carriers & $\varepsilon 4$-carriers & $P$ - value & Non-carriers & $\varepsilon 4$-carriers & $P$-value & Non-carriers & $\varepsilon 4$-carriers & $P$-value \\
\hline Baseline $(n=225 / 493)$ & $23.3(23.0,23.5)$ & $23.4(23.2,23.6)$ & 0.326 & & & & & & \\
\hline 2 months $(n=213 / 469)$ & $24.0(23.6,24.4)$ & $24.0(23.8,24.3)$ & 0.843 & $0.64(0.28,1.00)$ & $0.60(0.39,0.80)$ & 0.834 & 73.2 & 72.7 & 0.926 \\
\hline 6 months $(n=194 / 423)$ & $23.5(23.0,23.9)$ & $23.5(23.2,23.9)$ & 0.864 & $0.20(-0.20,0.59)$ & $0.17(-0.12,0.46)$ & 0.920 & 61.9 & 65.2 & 0.417 \\
\hline 12 months ( $n=178 / 388)$ & $22.7(22.1,23.3)$ & $22.9(22.5,23.3)$ & 0.597 & $-0.53(-1.10,0.04)$ & $-0.56(-0.89,-0.22)$ & 0.945 & 56.2 & 54.4 & 0.716 \\
\hline 18 months $(n=145 / 320)$ & $21.7(20.9,22.5)$ & $22.3(21.9,22.8)$ & 0.189 & $-1.53(-2.29,-0.78)$ & $-1.18(-1.57,-0.80)$ & 0.420 & 49.0 & 46.3 & 0.617 \\
\hline 24 months ( $n=130 / 292)$ & $21.0(20.0,22.0)$ & $21.5(21.0,22.1)$ & 0.361 & $-2.52(-3.45,-1.60)$ & $-2.05(-2.54,-1.57)$ & 0.377 & 44.6 & 40.8 & 0.522 \\
\hline 30 months $(n=97 / 219)$ & $21.5(20.5,22.5)$ & $20.9(20.2,21.6)$ & 0.342 & $-2.04(-3.03,-1.05)$ & $-2.74(-3.36,-2.11)$ & 0.230 & 47.4 & 34.7 & 0.034 \\
\hline \multirow[t]{2}{*}{36 months $(n=91 / 199)$} & $21.0(19.9,22.2)$ & $20.3(19.6,21.1)$ & 0.325 & $-2.81(-3.83,-1.80)$ & $-3.26(-3.95,-2.57)$ & 0.471 & 35.2 & 31.7 & 0.591 \\
\hline & \multicolumn{3}{|c|}{ ADAS-cog (0 to 70$)$ score $^{a}$} & \multicolumn{3}{|c|}{$\begin{array}{c}\text { ADAS-cog (0 to } 70) \text { score, change from } \\
\text { baseline }^{\mathrm{a}}\end{array}$} & \multicolumn{3}{|c|}{$\begin{array}{c}\text { ADAS-cog (0 to } 70) \text { score, improved/unchanged } \\
\text { patients (\%) }\end{array}$} \\
\hline Number of non-carriers/ $\varepsilon 4$-carriers ${ }^{b}$ & Non-carriers & $\varepsilon 4$-carriers & P-value & Non-carriers & $\varepsilon 4$-carriers & $P$-value & Non-carriers & $\varepsilon 4$-carriers & $P$-value \\
\hline Baseline ( $n=220 / 488)$ & $17.8(17.0,18.6)$ & $17.1(16.6,17.7)$ & 0.220 & & & & & & \\
\hline 6 months $(n=187 / 414)$ & $16.8(15.9,17.8)$ & $17.6(16.8,18.3)$ & 0.277 & $0.84(0.09,1.58)$ & $-0.57(-1.22,0.08)$ & 0.011 & 63.0 & 51.5 & 0.010 \\
\hline 12 months $(n=171 / 376)$ & $18.1(16.8,19.4)$ & $18.5(17.6,19.3)$ & 0.666 & $0.06(-0.84,0.96)$ & $-1.78(-2.50,-1.05)$ & 0.004 & 57.7 & 44.5 & 0.005 \\
\hline 18 months $(n=137 / 306)$ & $19.4(17.7,21.1)$ & $19.5(18.5,20.5)$ & 0.893 & $-1.88(-3.30,-0.47)$ & $-2.89(-3.68,-2.11)$ & 0.185 & 48.1 & 38.8 & 0.075 \\
\hline 24 months $(n=117 / 274)$ & $20.4(18.2,22.5)$ & $20.1(18.9,21.3)$ & 0.812 & $-3.34(-4.98,-1.70)$ & $-4.07(-4.96,-3.18)$ & 0.409 & 43.5 & 33.3 & 0.065 \\
\hline 30 months $(n=92 / 203)$ & $20.7(18.3,23.1)$ & $21.7(20.1,23.3)$ & 0.526 & $-3.71(-5.85,-1.58)$ & $-5.54(-6.87,-4.22)$ & 0.139 & 42.2 & 28.7 & 0.031 \\
\hline \multirow[t]{2}{*}{36 months $(n=85 / 180)$} & $20.9(18.2,23.5)$ & $22.2(20.3,24.0)$ & 0.427 & $-4.96(-7.24,-2.68)$ & $-6.78(-8.28,-5.29)$ & 0.181 & 40.5 & 26.8 & 0.032 \\
\hline & \multicolumn{3}{|c|}{ IADL score ${ }^{a}$} & \multicolumn{3}{|c|}{ IADL score, change from baseline $e^{a}$} & \multicolumn{3}{|c|}{ IADL score, improved/unchanged patients (\%) } \\
\hline Number of non-carriers/દ4-carriers ${ }^{b}$ & Non-carriers & ع4-carriers & $P$-value & Non-carriers & $\varepsilon 4$-carriers & $P$-value & Non-carriers & $\varepsilon 4$-carriers & $P$-value \\
\hline Baseline ( $n=219 / 481)$ & $15.3(14.7,16.0)$ & $14.3(13.8,14.7)$ & 0.010 & & & & & & \\
\hline 6 months $(n=189 / 413)$ & $16.3(15.6,17.0)$ & $15.5(15.0,16.0)$ & 0.081 & $-1.07(-1.45,-0.69)$ & $-1.14(-1.41,-0.88)$ & 0.758 & 48.1 & 50.6 & 0.597 \\
\hline 12 months $(n=175 / 379)$ & $17.6(16.8,18.4)$ & $16.8(16.2,17.4)$ & 0.123 & $-2.31(-2.80,-1.82)$ & $-2.55(-2.93,-2.16)$ & 0.482 & 34.3 & 34.8 & 0.923 \\
\hline 18 months $(n=142 / 311)$ & $18.6(17.6,19.6)$ & $17.6(16.9,18.3)$ & 0.099 & $-3.64(-4.29,-2.99)$ & $-3.63(-4.09,-3.16)$ & 0.974 & 26.6 & 23.4 & 0.477 \\
\hline 24 months ( $n=128 / 283$ ) & $19.8(18.7,20.9)$ & $18.4(17.7,19.1)$ & 0.029 & $-5.13(-5.96,-4.29)$ & $-4.60(-5.10,-4.10)$ & 0.268 & 18.4 & 17.9 & 0.889 \\
\hline 30 months $(n=95 / 216)$ & $19.9(18.7,21.1)$ & $19.1(18.3,19.9)$ & 0.273 & $-5.11(-6.07,-4.15)$ & $-5.71(-6.34,-5.09)$ & 0.301 & 16.3 & 14.4 & 0.728 \\
\hline 36 months $(n=91 / 191)$ & $20.3(18.9,21.7)$ & $19.7(18.8,20.6)$ & 0.500 & $-6.23(-7.31,-5.14)$ & $-6.31(-7.03,-5.60)$ & 0.895 & 17.0 & 12.1 & 0.266 \\
\hline
\end{tabular}

${ }^{a}$ Mean (95\% confidence interval).

${ }^{b}$ No difference in dropout was found between APOE $\varepsilon 4$-carriers and non-carriers, $X^{2}(1)=0.148, P=0.700$.

For clarity, clinical improvements for all scales have been tabulated as positive changes from the start of ChEl treatment (baseline).

ADAS-cog, Alzheimer's Disease Assessment Scale-cognitive subscale; APOE, apolipoprotein E; ChEI, cholinesterase inhibitor; IADL, Instrumental Activities of Daily Living scale; MMSE, Mini-Mental State Examination. 


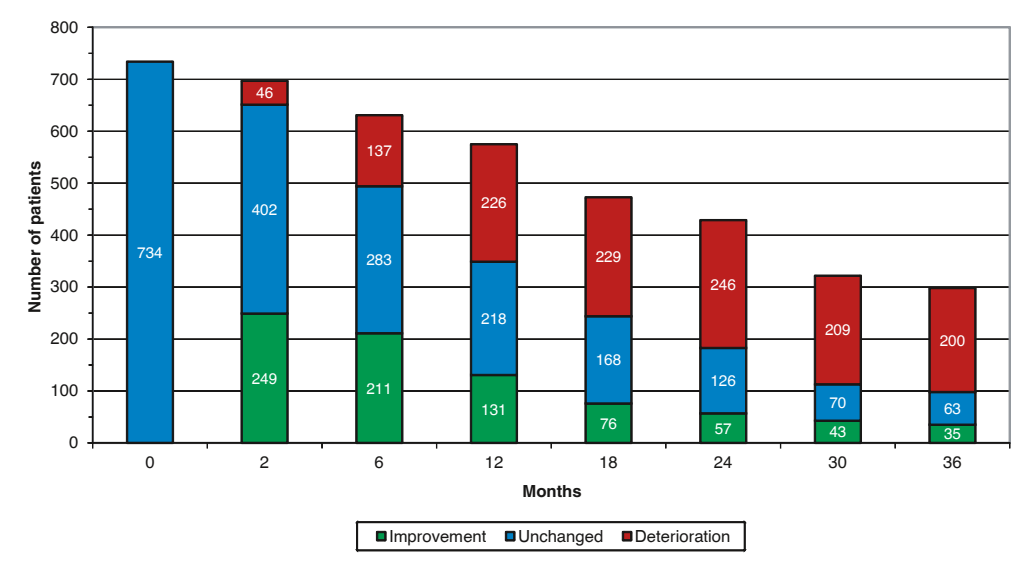

Figure 2 CIBIC, changes in global performance. The changes in global performance (CIBIC) from the start of ChEl treatment over three years in mild AD. CIBIC score 1 to 3 was considered as improvement, 4 as unchanged and 5 to 7 as deterioration. Among the remaining patients in the study, 61\% exhibited global improvement or no changes after one year, $43 \%$ after two years and 33\% after three years of ChEl therapy. AD, Alzheimer's disease; ChEl, cholinesterase inhibitor; CIBIC, Clinician's Interview-Based Impression of Change.

points more favorable for a 65 -year-old vs an 85 -year-old individual.

Furthermore, there was an interaction effect between years of education and time in the study. A higher level of education implied increased cognitive and functional impairments over time. For example, a patient with 15 years of education exhibited an additional 1.6 points of MMSE, 2.7 points of ADAS-cog and 2.2 points of IADL mean deterioration after 3 years compared with an individual with 9 years of education.

If not otherwise specified, the arbitrary examples presented in these calculations were based on an average patient that was aged 75 years, was a carrier of the APOE $\varepsilon 4$ allele, living with a family member, had 10 years of education, exhibited an MMSE score of 23, ADAS-cog score of 18, IADL score of 15 , and received $65 \%$ of the maximum recommended dose of ChEI.

The background variables age at onset, number of medications and specific concomitant medications, type of ChEI agent, type of ChEI $\times$ dose and the interaction effects of gender or APOE genotype with disease severity or time in the study were not significant when included in the mixed-effects models.

\section{Prediction models}

Non-linear regression models for calculation of the predicted MMSE, ADAS-cog or IADL score for a cohort of ChEI-treated mild AD patients, based on the respective baseline score are provided. These equations intend to predict the scores at subsequent assessments over a three-year period. The models explained a substantial degree of variance in the data set, that is, demonstrated a good fit, MMSE: $\left(\mathrm{R}^{2}=0.261, \mathrm{R}=0.511, P<0.001\right)$, ADAS-cog: $\left(\mathrm{R}^{2}=0.385, \mathrm{R}=0.621, P<0.001\right)$, and IADL: $\left(\mathrm{R}^{2}=0.592, \mathrm{R}=0.769, P<0.001\right)$.
Predicted MMSE score:

$$
\begin{aligned}
\hat{\mathrm{Y}}= & 7.6014-(0.4374 \times \mathrm{t})+\left(0.7116 \times \mathrm{x}_{\mathrm{i}}\right) \\
& +\left(0.0138 \times \mathrm{tx}_{\mathrm{i}}\right)
\end{aligned}
$$

Predicted ADAS-cog score:

$$
\begin{aligned}
\hat{\mathrm{Y}}= & 2.7835-(0.0537 \times \mathrm{t}) \\
& +\left(0.8867 \times \mathrm{x}_{\mathrm{i}}\right)-\left(0.0073 \times \mathrm{x}_{\mathrm{i}}^{2}\right)+\left(0.0161 \times \mathrm{tx}_{\mathrm{i}}\right)
\end{aligned}
$$

Predicted IADL score:

$$
\begin{aligned}
\hat{\mathrm{Y}}= & -6.1756+(0.3140 \times \mathrm{t}) \\
& +\left(1.8752 \times \mathrm{x}_{\mathrm{i}}\right)-\left(0.0023 \times \mathrm{t}^{2}\right)-\left(0.0299 \times \mathrm{x}_{\mathrm{i}}^{2}\right)-\left(0.0032 \times \mathrm{tx}_{\mathrm{i}}\right)
\end{aligned}
$$

Where $\mathrm{t}=$ time in months between the baseline score and the actual visit, $x_{i}=$ baseline MMSE (ADAS-cog or IADL) score.

The MMSE and ADAS-cog prediction models are illustrated in Figure 3a, b, respectively. The SATS patients' actual mean scores with $95 \%$ CI are also presented in the figures, together with expected decline in untreated individuals. Regarding MMSE, a reported deterioration of 1.4 to 1.8 points per year in mild $\mathrm{AD}$ was used [23], and the predicted ADAS-cog decline was calculated based on two previously reported baselinedependent empirical models of untreated AD [24,25].

\section{Discussion}

In this three-year study of ChEI treatment in mild $\mathrm{AD}$ in a routine clinical setting, we found that patients' cognitive ability and global performance were more preserved than their functional capacity. Using mixed-effects models, we found that a higher mean dose of ChEI (regardless of drug agent) and a lower level of education were predictors of more preserved longitudinal cognitive and 
Table 4 Factors affecting the long-term outcome with MMSE, ADAS-cog or IADL score as dependent variables

\begin{tabular}{|c|c|c|c|c|c|c|}
\hline & MMSE & & ADA & & IADL & \\
\hline Percentage of variance accounted for, all fixed terms & $28.6 \%, P<0.001$ & & $37.6 \%, P<0.001$ & & $60.9 \%, P<0.001$ & \\
\hline Significant predictors in final mixed models ${ }^{\mathrm{a}}$ & $\beta(95 \% \mathrm{Cl})$ & $P$-value & $\beta(95 \% \mathrm{Cl})$ & $P$-value & $\beta(95 \% \mathrm{Cl})$ & $P$-value \\
\hline \multicolumn{7}{|l|}{ Fixed terms } \\
\hline \multirow[t]{2}{*}{ Intercept } & -25.751 & 0.022 & -14.101 & 0.048 & 0.808 & 0.728 \\
\hline & $(-47.709,-3.793)$ & & $(-28.099,-0.102)$ & & $(-3.747,5.363)$ & \\
\hline \multirow[t]{2}{*}{ Time in months from baseline } & -0.924 & $<0.001$ & 0.480 & 0.019 & 0.154 & $<0.001$ \\
\hline & $(-1.201,-0.648)$ & & $(0.078,0.881)$ & & $(0.069,0.239)$ & \\
\hline \multirow[t]{2}{*}{ Baseline assessment score } & 2.198 & $<0.001$ & 1.696 & $<0.001$ & 1.530 & $<0.001$ \\
\hline & $(1.272,3.124)$ & & $(0.931,2.462)$ & & $(1.262,1.798)$ & \\
\hline \multirow[t]{2}{*}{ Baseline assessment score ${ }^{2}$} & & ns & & ns & -0.021 & $<0.001$ \\
\hline & & & & & $(-0.029,-0.013)$ & \\
\hline \multirow[t]{2}{*}{ Time in months $\times$ Baseline assessment score } & 0.028 & $<0.001$ & 0.014 & $<0.001$ & -0.001 & 0.512 \\
\hline & $(0.019,0.036)$ & & $(0.008,0.021)$ & & $(-0.005,0.003)$ & \\
\hline \multirow[t]{2}{*}{ Time in months ${ }^{2} \times$ Baseline assessment score } & -0.00007 & $<0.001$ & 0.0002 & 0.002 & -0.00006 & 0.043 \\
\hline & $(-0.0001,-0.00004)$ & & $(0.00006,0.0003)$ & & $(-0.0001,-0.000002)$ & \\
\hline \multicolumn{7}{|l|}{ Background variables: } \\
\hline \multirow[t]{2}{*}{ Gender $($ male $=0$, female $=1)$} & -0.582 & 0.001 & & ns & & ns \\
\hline & $(-0.233,-0.931)$ & & & & & \\
\hline \multirow[t]{2}{*}{ APOE $\varepsilon 4$ carrier ( $n o=0$, yes $=1$ ) } & & ns & 1.278 & 0.015 & & ns \\
\hline & & & $(2.307,0.249)$ & & & \\
\hline \multirow[t]{2}{*}{ Solitary living $(\mathrm{no}=0$, yes $=1$ ) } & & ns & & ns & 0.776 & 0.001 \\
\hline & & & & & $(1.253,0.299)$ & \\
\hline \multirow[t]{2}{*}{ Education (years) } & 0.089 & 0.011 & -0.111 & 0.281 & -0.051 & 0.328 \\
\hline & $(0.021,0.158)$ & & $(-0.312,0.090)$ & & $(-0.152,0.051)$ & \\
\hline \multirow[t]{2}{*}{ Time in months $\times$ Education, years } & -0.010 & 0.002 & 0.016 & 0.017 & 0.011 & 0.001 \\
\hline & $(-0.016,-0.004)$ & & $(0.003,0.028)$ & & $(0.005,0.018)$ & \\
\hline \multirow[t]{2}{*}{ Age at first assessment (years) } & 0.491 & 0.001 & 0.285 & 0.002 & 0.042 & 0.023 \\
\hline & $(0.202,0.780)$ & & $(0.101,0.469)$ & & $(0.006,0.078)$ & \\
\hline \multirow[t]{2}{*}{ Time in months $\times$ Age } & 0.004 & 0.003 & -0.009 & $<0.001$ & & ns \\
\hline & $(0.001,0.006)$ & & $(-0.014,-0.004)$ & & & \\
\hline \multirow[t]{2}{*}{ Baseline assessment score $\times$ Age } & -0.022 & $<0.001$ & -0.015 & 0.004 & & ns \\
\hline & $(-0.034,-0.010)$ & & $(-0.025,-0.005)$ & & & \\
\hline
\end{tabular}

328

ns


Table 4 Factors affecting the long-term outcome with MMSE, ADAS-cog or IADL score as dependent variables (Continued)

\begin{tabular}{|c|c|c|c|c|c|c|}
\hline \multirow[b]{2}{*}{ Significant predictors in final mixed models ${ }^{a}$} & \multicolumn{2}{|c|}{ MMSE } & \multicolumn{2}{|c|}{ ADAS-cog } & \multicolumn{2}{|c|}{ IADL } \\
\hline & $\beta(95 \% \mathrm{Cl})$ & $P$-value & $\beta(95 \% \mathrm{Cl})$ & $P$-value & $\beta(95 \% \mathrm{Cl})$ & $P$-value \\
\hline \multirow[t]{2}{*}{ IADL score at baseline } & -0.098 & $<0.001$ & 0.225 & $<0.001$ & na & \\
\hline & $(-0.135,-0.062)$ & & $(0.117,0.332)$ & & & \\
\hline \multirow[t]{2}{*}{ MMSE score at baseline } & na & & na & & -0.238 & $<0.001$ \\
\hline & & & & & $(-0.358,-0.118)$ & \\
\hline \multirow[t]{2}{*}{ ChEl dose $^{b}$} & 0.010 & 0.049 & -0.044 & 0.002 & -0.013 & 0.048 \\
\hline & $(0.00004,0.019)$ & & $(-0.071,-0.017)$ & & $(-0.026,-0.0001)$ & \\
\hline \multicolumn{7}{|l|}{ Random terms (variance) } \\
\hline \multirow[t]{2}{*}{ Intercept } & 2.097 & $<0.001$ & 17.298 & $<0.001$ & 5.539 & $<0.001$ \\
\hline & $(1.647,2.669)$ & & $(13.849,21.606)$ & & $(4.473,6.858)$ & \\
\hline \multirow[t]{2}{*}{ Time in months } & 0.026 & $<0.001$ & 0.086 & $<0.001$ & 0.027 & $<0.001$ \\
\hline & $(0.022,0.031)$ & & $(0.071,0.104)$ & & $(0.022,0.032)$ & \\
\hline
\end{tabular}

Age at onset, number of medications and specific concomitant medications used at baseline and the variable comparing the ChEl agents were not significant.

$\beta$ values were unstandardized and are expressed per one unit increase for continuous variables and for the condition present in dichotomous variables.

aBaseline assessment score $=$ MMSE, ADAS-cog or IADL, respectively.

${ }^{\mathrm{b}}$ Mean percentage of the maximum recommended dose, that is, $10 \mathrm{mg}$ for donepezil, $12 \mathrm{mg}$ for rivastigmine and $24 \mathrm{mg}$ for galantamine.

Abbreviations: ADAS-cog, Alzheimer's Disease Assessment Scale-cognitive subscale; APOE, apolipoprotein E; ChEl, cholinesterase inhibitors; Cl, confidence interval; IADL, Instrumental Activities of Daily Living; MMSE, Mini-Mental State Examination; na not applicable; ns not significant. 

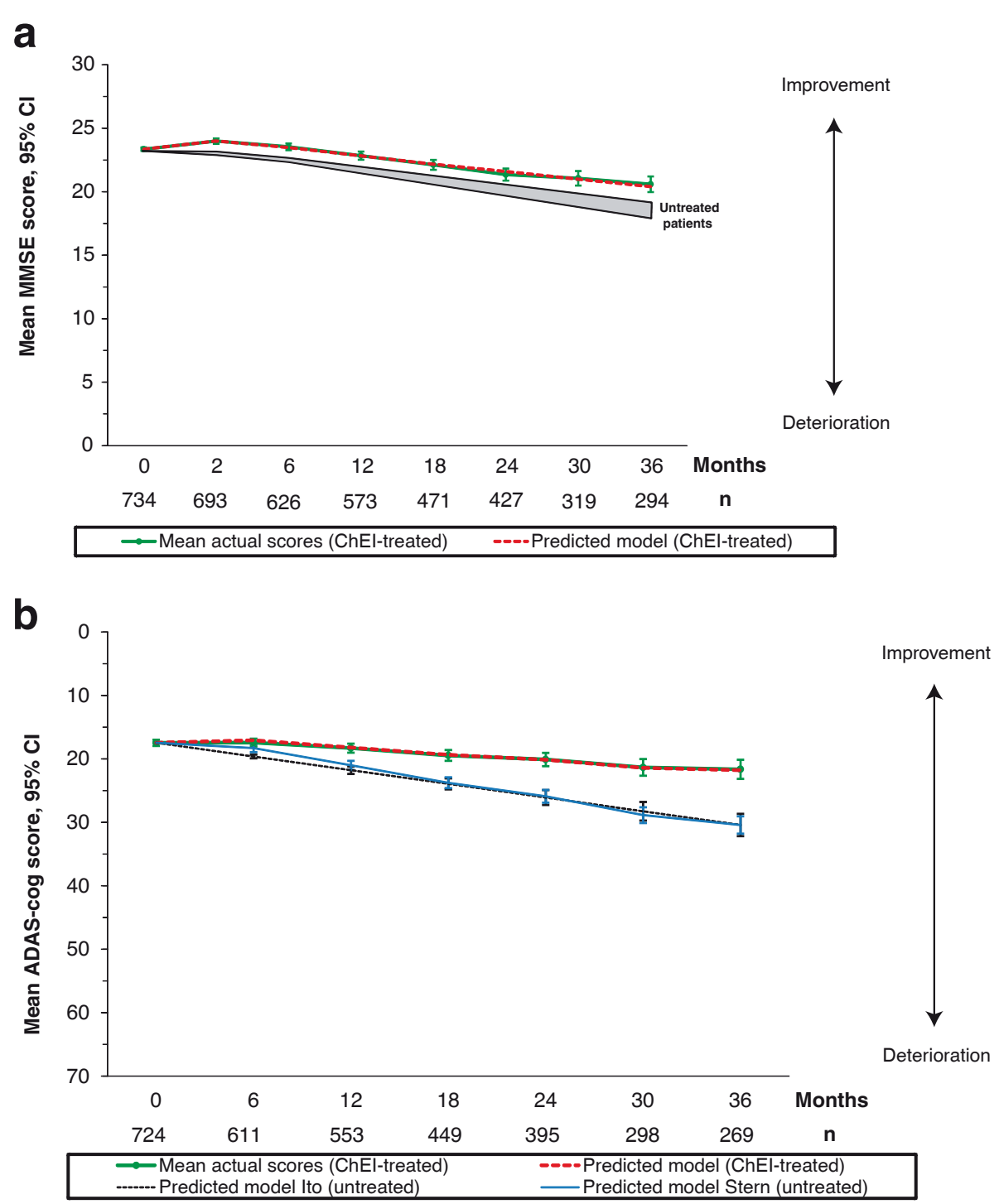

Figure 3 Prediction of cognitive outcome during three years of ChEl treatment. a) Predicted MMSE mean scores calculated from our nonlinear regression model of ChEl-treated mild AD patients. The participants' actual mean scores with $95 \% \mathrm{Cl}$ are also presented in the figure. The shaded area shows the decline of 1.4 to 1.8 MMSE points/year based on historical untreated individuals with mild AD [23]. b) Predicted ADAScog mean scores calculated from our non-linear regression model of ChEl-treated mild AD patients. Their actual mean scores with $95 \% \mathrm{Cl}$ are also presented in the figure. The mean predicted scores with 95\% Cl from two baseline-dependent prediction models of untreated AD patients are also included in the figure for comparison [24,25]. AD, Alzheimer's disease; ADAS-cog, Alzheimer's Disease Assessment Scale-cognitive subscale; ChEl, cholinesterase inhibitor; MMSE, Mini-Mental State Examination.

functional abilities. Older individuals or those with less impaired IADL at baseline exhibited a slower progression rate in cognition, while younger age, living with a family member and higher cognitive status at baseline were predictors of less functional deterioration during the study. Inconsistent results regarding cognitive outcome were found between genders and APOE genotype. Regression models of expected decline in mild AD are presented.

There has been increased interest in disease progression in mild AD after new therapies such as solanezumab and souvenaid have shown positive results in this group exclusively. In the present study of mild AD, which includes all three ChEI agents, the three-year decline in ADAS-cog was 6.12 points and MMSE 3.10 points, suggesting a similar rate of change as in our previously described mild-tomoderate SATS group [10,26]. The US Food and Drug Administration has defined an improvement of at least four points in the ADAS-cog score as clinically significant (reported in $[27,28]$ ), and a MMSE change of three points has been suggested to indicate a clinically significant alteration in cognitive ability [29,30]. From the Alzheimer's 
Disease Neuroimaging Initiative, Schneider et al. [31] reported that the ChEI-treated participants with mild AD deteriorated, on average, 9.25 points in ADAS-cog and 4.19 points in MMSE scores after two years in the study. The corresponding two-year mean decline in our cohort was considerably less, 3.81 and 2.20 points, respectively. An 18-month randomized controlled trial of tarenflurbil in mild AD showed 6.44 points ADAS-cog and 3.27 points MMSE mean deterioration in the placebo group (most patients were treated with ChEIs and/or memantine) [32]. As a comparison, our study showed, on average, lower deterioration after 18 months, 2.58 and 1.31 points, respectively. However, participants were included in these studies 1 year (median) and 20.5 months (mean) after AD diagnosis. Thus, these patients had been treated with ChEIs and/ or memantine before the baseline, whereas the baseline in the SATS was the start of ChEI therapy. The slower disease progression observed in the SATS cohort might reflect the benefits of continuous ChEI therapy started almost immediately after $\mathrm{AD}$ diagnosis and the positive treatment response in the first months after initiation (baseline).

The current study of mild AD highlights the importance of not only assessing cognition at follow-ups, but also IADL capacity. A moderate linear relationship $(r=0.4$ to 0.7 ) between cognitive and functional abilities has been observed in both untreated [33] and ChEI-treated [34] AD patients. Our study demonstrated that individuals with higher cognitive status at the start of ChEI therapy showed greater preserved IADL capacity over time and that those with a better IADL score at baseline exhibited a slower rate of cognitive decline. Patients showing a rapid functional decline have previously been shown to exhibit significantly greater impairment of cognitive ability at the time of $\mathrm{AD}$ diagnosis $[11,35,36]$. This relationship indicates that various aspects of the patients' capabilities (cognitive, global, IADL) should be analyzed using multivariate methods, and these aspects should be interpreted simultaneously because a change in one ability might affect a change in another.

In the present ChEI-treated cohort with MMSE score 20 to 26, the rate of deterioration in IADL was faster than in cognitive ability and global performance. A marked decline in IADL capacity was also reported in the above-mentioned studies of mild AD [31,32]. Functional deficits have been observed as early as in amnestic mild cognitive impairment [37]. Three years after AD diagnosis, $70 \%$ to $85 \%$ of the remaining individuals in our mild SATS cohort could not carry out IADL tasks independently. The number of concomitant medications and usage of specific medications at baseline were not significant predictors of progression in IADL in the multivariate mixed-effects models in the current study, suggesting that comorbidity did not influence the functional outcome. These findings emphasize the importance of functional evaluations even for patients in the mild stage of $\mathrm{AD}$ in clinical routine, and raise the question of whether IADL is a better and more sensitive outcome measure than cognition in studies of potentially 'disease-modifying' therapies.

The rate of disease progression varies among AD patients. In particular, knowledge of prognostic factors in mild AD exclusively is strongly limited. This study shows that male gender, older age, a lower level of education, absence of the APOE $\varepsilon 4$ allele, more preserved IADL ability and a higher mean dose of ChEI were significant predictors of slower cognitive decline. Younger age, lower educational level, living with a family member, better cognitive status and a higher ChEI dose were predictors of less functional deterioration. These findings are consistent with previous papers from the SATS including the entire mild-to-moderate cohort $[11,38]$. Using a mixed-models approach, Wilkosz et al. [39] also observed that male sex and older age were predictors of a slower longitudinal cognitive decline in AD. Several other studies also reported a more rapid rate of cognitive deterioration in younger individuals [40,41], but not all found that age was a significant predictor of decline [42]. It is reasonable to predict that when $\mathrm{AD}$ is manifest at younger ages, more hereditary early-onset and fast progression subtypes of the disease affect the outcome and could lead to a worse prognosis in mild AD as well. Our finding that a lower education level was related to a slower rate of cognitive deterioration was in agreement with a community-based study of mild dementia [43]. Lower education has also been reported to be associated with slower progression in mild-to-moderate AD $[41,44]$. Patients with low education level were assumed to have a reduced cognitive reserve and, therefore, would be more vulnerable to the effects of neurodegeneration. They would also be expected to perform worse on standardized cognitive tests that use a single threshold to identify dementia, such as the MMSE and ADAS-cog. These consequences of a lower education level might lead to an earlier manifestation of the typical symptoms of $\mathrm{AD}$ and detection of the disease. Furthermore, diagnosis and treatment might occur in an earlier stage, which may improve the results of AD therapy. The participants' high level of education in the studies of mild AD from the United States $[31,32]$ might be one reason for their faster cognitive decline compared with the SATS cohort. Impairment in several cognitive domains and its relation to level of education can already be observed several years before the clinical diagnosis of AD [45].

In the current study, the presence of at least one APOE $\varepsilon 4$ allele was associated with a faster rate of cognitive decline when using the ADAS-cog scale but not 
the MMSE. Reports of the association of the $\varepsilon 4$ allele with cognitive deterioration in the literature vary. Some studies report a positive relationship of APOE $\varepsilon 4$ with more rapid cognitive decline in mild [46] and mild-tomoderate AD [47], while others report no significant influence on the rate of cognitive and functional progression $[48,49]$, or that individuals with two $\varepsilon 4$ alleles have a slower clinical course of AD [50]. Explorative analyses based on phase 2 data from passive immunization with the anti-A $\beta$ antibody bapineuzumab found that noncarriers of the APOE $\varepsilon 4$ allele had a better cognitive response compared with $\varepsilon 4$-carriers after 18 months [12]; however, the phase 3 trials failed to replicate these results [51]. Yet, the treatment groups have been stratified into presence/absence of the APOE $\varepsilon 4$ allele in some immunotherapy studies [52]. In our naturalistic SATS study including ChEI-treated patients with mild-tomoderate AD, APOE \&4-carriers exhibited both a lower cognitive response after six months of treatment and poorer long-term outcome after three years. On average, these individuals were younger at the start of ChEI treatment and had a higher level of education than the non- $\varepsilon 4$ carriers [38]. A recent study of functional ability in amnestic mild cognitive impairment showed that patients carrying the APOE $\varepsilon 4$ allele had more IADL deficits compared with non-carriers [37]. These findings highlight the importance of using an advanced multivariate statistical method, such as a mixedeffects model, to be able to take the potential predictive characteristics into account when analyzing disease progression [53]. The better response to drug agents observed in patients with no APOE $\varepsilon 4$ alleles might not be a therapeutic effect, but possibly a slower natural decline.

Higher doses of ChEIs were related to a more favorable long-term cognitive and functional outcome in this study of mild AD. These results were also observed in the entire mild-to-moderate SATS cohort $[11,38]$ as well as in a meta-analysis of randomized trials [54]. Moreover, a higher ChEI dose was associated with a delay in the need for nursing home placement [21,55]. A recent study from our group reported for the first time a significant relationship between a higher dose of ChEI and less need for home help services [56]. These effects and consequences show the importance of optimizing the ChEI dose for the individual patient with AD.

The advantages of the present three-year treatment study are the prospective, well-structured, regular sixmonth evaluations of a large cohort of continuously ChEI-treated mild AD patients from Swedish memory clinics. We enrolled more ordinary patients than the specially selected individuals usually included in clinical trials by using wide inclusion criteria, and allowing concomitant illnesses and medications. Moreover, the compliance to ChEI treatment in the SATS cohort was high [57]. The completion rate of $42 \%$ obtained for these participants from clinical practice was high compared with other AD extension or naturalistic studies [26]. The large attrition rate in all long-term AD studies may contribute to a better outcome for the patients remaining in the study, assuming that they benefit more from ChEI therapy. The SATS is an observational, non-randomized study, and has the limitations of an open-label design, and no untreated placebo group because of ethical concerns, similar to other AD therapy studies longer than six months. The choice of the ChEI agent and dose was left entirely to the individual physician's discretion and professional judgment.

In the future, research efforts will focus on the development of AD starting in the early and pre-symptomatic stages. The timing of the start of therapy during the course of AD appears to be an essential factor that influences disease progression and the outcome of clinical trials. Currently, new pharmacological agents, such as immunotherapies, are being evaluated in randomized trials in addition to standard therapy (ChEI and/or memantine). Long-term observational studies of ChEItreated $\mathrm{AD}$ patients exclusively in the milder stages are warranted to demonstrate realistic treatment expectations. The baseline-dependent prediction models of mild AD presented in the current study might be a useful tool to estimate the cognitive and functional outcomes that may be expected using ChEI monotherapy over time.

\section{Conclusions}

In conclusion, an investigation of disease progression in different domains was described in this mild AD study. Our naturalistic SATS cohort exhibited a slower cognitive decline in comparison with those previously reported in the literature; however, the patients in those studies had been treated with ChEIs and/or memantine prior to baseline and had different socio-demographic characteristics. When comparing changes in scores between studies, it may be important to consider the point of time when ChEI therapy was initiated because the first months of positive response after initiation could imply a more favorable mean outcome over time. This study shows that socio-demographic and clinical factors such as age, years of education and the dose of ChEI, previously shown to affect the trajectories in mild-to-moderate patients, might alter the outcomes of various mild $A D$ studies as well. The surprisingly fast deterioration in IADL compared with cognitive and global performance stresses the clinical importance of functional evaluations during the early stages of dementia. APOE genotype exhibited inconsistent results, which is noteworthy since this variable is used to select patients in $\mathrm{AD}$ trials. Information related to 
expected progression in various domains of the disease, and the influence of potential predictors, is necessary for evaluation of future treatments in mild AD. We present mathematical prediction models that could be used to assess the long-term outcomes of new therapies added to ChEI treatment.

\section{Abbreviations}

AD: Alzheimer's disease; ADAS-cog: Alzheimer's Disease Assessment Scale-cognitive subscale; APOE: Apolipoprotein E; ChEl: Cholinesterase inhibitors; Cl: Confidence interval; CIBIC: Clinician Interview-Based Impression of Change; IADL: Instrumental Activities of Daily Living Scale; MMSE: Mini-Mental State Examination; NINCDS-ADRDA: National Institute of Neurological and Communicative Disorders and Stroke and the Alzheimer's Disease and Related Disorders Association; NSAIDs: Non-steroidal anti-inflammatory drugs; SATS: Swedish Alzheimer Treatment Study; SD: Standard deviation; SPSS: Statistical Package for the Social Sciences.

\section{Competing interests}

The authors declare that they have no competing interests.

\section{Authors' contributions}

CW participated in the study, supervised the data collection, was responsible for the statistical design and for carrying out the statistical analyses, interpreted the results and drafted the paper. ÅKW participated in the study, assisted in analyzing and interpreting the data, and critically revised the manuscript. LM designed the study and critically revised the manuscript. All authors read and approved the final manuscript.

\section{Acknowledgements}

CW has received an ALF young researcher grant from Region Skåne, Sweden. The sponsor had no involvement in the study design, in the collection, analysis and interpretation of data, in the writing of the report or in the decision to submit the manuscript. We wish to thank all the SATS patients and their relatives for their cooperation in this study. The authors are grateful to the staff from all of the different centers taking part in the management of the patients and providing administrative support in the study.

Received: 5 July 2013 Accepted: 12 September 2013 Published: 07 Oct 2013

\section{References}

1. Rosenstein LD: Differential diagnosis of the major progressive dementias and depression in middle and late adulthood: a summary of the literature of the early 1990s. Neuropsychol Rev 1998, 8:109-167.

2. Birks J: Cholinesterase inhibitors for Alzheimer's disease. Cochrane Database Syst Rev 2006:CD005593.

3. Tayeb HO, Yang HD, Price BH, Tarazi Fl: Pharmacotherapies for Alzheimer's disease: beyond cholinesterase inhibitors. Pharmacol Ther 2012, 134:8-25.

4. Holmes C, Boche D, Wilkinson D, Yadegarfar G, Hopkins V, Bayer A, Jones RW, Bullock R, Love S, Neal JW, Zotova E, Nicoll JA: Long-term effects of Abeta42 immunisation in Alzheimer's disease: follow-up of a randomised, placebo-controlled phase I trial. Lancet 2008, 372:216-223.

5. Vellas B, Carrillo MC, Sampaio C, Brashear HR, Siemers E, Hampel H, Schneider LS, Weiner M, Doody R, Khachaturian Z, Cedarbaum J, Grundman M, Broich K, Giacobini E, Dubois B, Sperling R, Wilcock GK, Fox N, Scheltens P, Touchon J, Hendrix S, Andrieu S, Aisen P, EU/US/CTAD Task Force Members: Designing drug trials for Alzheimer's disease: what we have learned from the release of the phase III antibody trials: a report from the EU/US/CTAD Task Force. Alzheimers Dement 2013, 9:438-444.

6. Scheltens P, Twisk JW, Blesa R, Scarpini E, Von Arnim CA, Bongers A, Harrison J, Swinkels SH, Stam CJ, De Waal H, Wurtman RJ, Wieggers RL, Vellas B, Kamphuis PJ: Efficacy of souvenaid in mild Alzheimer's disease: results from a randomized, controlled trial. J Alzheimers Dis 2012, 31:225-236

7. Raskind MA, Peskind ER, Truyen L, Kershaw P, Damaraju CV: The cognitive benefits of galantamine are sustained for at least 36 months: a longterm extension trial. Arch Neurol 2004, 61:252-256.
8. Pirttila T, Wilcock G, Truyen L, Damaraju CV: Long-term efficacy and safety of galantamine in patients with mild-to-moderate Alzheimer's disease: multicenter trial. Eur I Neurol 2004, 11:734-741.

9. Burns A, Gauthier S, Perdomo C: Efficacy and safety of donepezil over 3 years: an open-label, multicentre study in patients with Alzheimer's disease. Int J Geriatr Psychiatry 2007, 22:806-812.

10. Wallin AK, Andreasen N, Eriksson S, Båtsman S, Nasman B, Ekdahl A, Kilander L, Grut M, Rydén M, Wallin A, Jonsson M, Olofsson H, Londos E, Wattmo C, Eriksdotter Jonhagen M, Minthon L, Swedish Alzheimer Treatment Study Group: Donepezil in Alzheimer's disease: what to expect after 3 years of treatment in a routine clinical setting. Dement Geriatr Cogn Disord 2007, 23:150-160.

11. Wattmo C, Wallin AK, Londos E, Minthon L: Long-term outcome and prediction models of activities of daily living in Alzheimer disease with cholinesterase inhibitor treatment. Alzheimer Dis Assoc Disord 2011, 25:63-72.

12. Salloway S, Sperling R, Gilman S, Fox NC, Blennow K, Raskind M, Sabbagh M, Honig LS, Doody R, Van Dyck CH, Mulnard R, Barakos J, Gregg KM, Liu E, Lieberburg I, Schenk D, Black R, Grundman M, Bapineuzumab 201 Clinical Trial Investigators: A phase 2 multiple ascending dose trial of bapineuzumab in mild to moderate Alzheimer disease. Neurology 2009, 73:2061-2070.

13. Almkvist $\mathrm{O}$, Jelic V, Amberla K, Hellstrom-Lindahl E, Meurling L, Nordberg A: Responder characteristics to a single oral dose of cholinesterase inhibitor: a double-blind placebo-controlled study with tacrine in Alzheimer patients. Dement Geriatr Cogn Disord 2001, 12:22-32.

14. Rigaud AS, Traykov L, Latour F, Couderc R, Moulin F, Forette F: Presence or absence of at least one epsilon 4 allele and gender are not predictive for the response to donepezil treatment in Alzheimer's disease. Pharmacogenetics 2002, 12:415-420.

15. Folstein MF, Folstein SE, McHugh PR: "Mini-mental state": a practical method for grading the cognitive state of patients for the clinician. J Psychiatr Res 1975, 12:189-198.

16. Frances A, American Psychiatric Association: Diagnostic and Statistical Manual of Mental Disorders: DSM-IV. Prepared by the task force on DSM-IV. 4th edition. Washington, D.C: American Psychiatric Association; 1994.

17. McKhann G, Drachman D, Folstein M, Katzman R, Price D, Stadlan EM: Clinical diagnosis of Alzheimer's disease: report of the NINCDSADRDA work group under the auspices of Department of Health and Human Services Task Force on Alzheimer's Disease. Neurology 1984, 34:939-944

18. Rosen WG, Mohs RC, Davis KL: A new rating scale for Alzheimer's disease. Am J Psychiatry 1984, 141:1356-1364.

19. Knopman DS, Knapp MJ, Gracon SI, Davis CS: The Clinician Interview-Based Impression (CIBI): a clinician's global change rating scale in Alzheimer's disease. Neurology 1994, 44:2315-2321.

20. Lawton MP, Brody EM: Assessment of older people: self-maintaining and instrumental activities of daily living. Gerontologist 1969, 9:179-186.

21. Wattmo C, Wallin AK, Londos $E$, Minthon L: Risk factors for nursing home placement in Alzheimer's disease: a longitudinal study of cognition, ADL, service utilization, and cholinesterase inhibitor treatment. Gerontologist 2011, 51:17-27.

22. Laird NM, Ware JH: Random-effects models for longitudinal data. Biometrics 1982, 38:963-974.

23. Mendiondo MS, Ashford JW, Kryscio RJ, Schmitt FA: Modelling mini mental state examination changes in Alzheimer's disease. Stat Med 2000, 19:1607-1616.

24. Stern RG, Mohs RC, Davidson M, Schmeidler J, Silverman J, Kramer-Ginsberg E, Searcey T, Bierer L, Davis KL: A longitudinal study of Alzheimer's disease: measurement, rate, and predictors of cognitive deterioration. Am J Psychiatry 1994, 151:390-396.

25. Ito K, Ahadieh S, Corrigan B, French J, Fullerton T, Tensfeldt T: Disease progression meta-analysis model in Alzheimer's disease. Alzheimers Dement 2010, 6:39-53.

26. Wallin AK, Wattmo C, Minthon L: Galantamine treatment in Alzheimer's disease: response and long-term outcome in a routine clinical setting. Neuropsychiatr Dis Treat 2011, 7:565-576.

27. Wilcock GK, Lilienfeld S, Gaens E: Efficacy and safety of galantamine in patients with mild to moderate Alzheimer's disease: multicentre randomised controlled trial: Galantamine International-1 study group. BMJ 2000, 321:1445-1449. 
28. Tariot PN: Maintaining cognitive function in Alzheimer disease: how effective are current treatments? Alzheimer Dis Assoc Disord 2001, 15(Suppl 1):S26-S33.

29. Qaseem A, Snow V, Cross JT Jr, Forciea MA, Hopkins R Jr, Shekelle P, Adelman A, Mehr D, Schellhase K, Campos-Outcalt D, Santaguida P, Owens DK, American College of Physicians/American Academy of Family Physicians Panel on Dementia: Current pharmacologic treatment of dementia: a clinical practice guideline from the American College of Physicians and the American Academy of Family Physicians. Ann Intern Med 2008, 148:370-378.

30. Palmqvist S, Minthon L, Wattmo C, Londos E, Hansson O: A quick test of cognitive speed is sensitive in detecting early treatment response in Alzheimer's disease. Alzheimers Res Ther 2010, 2:29.

31. Schneider LS, Insel PS, Weiner MW: Alzheimer's disease neuroimaging I: treatment with cholinesterase inhibitors and memantine of patients in the Alzheimer's disease neuroimaging initiative. Arch Neurol 2011, 68:58-66.

32. Green RC, Schneider LS, Amato DA, Beelen AP, Wilcock G, Swabb EA, Zavitz $\mathrm{KH}$, Tarenflurbil Phase 3 Study Group: Effect of tarenflurbil on cognitive decline and activities of daily living in patients with mild Alzheimer disease: a randomized controlled trial. JAMA 2009, 302:2557-2564.

33. Galasko D, Corey-Bloom J, Thal LJ: Monitoring progression in Alzheimer's disease. J Am Geriatr Soc 1991, 39:932-941.

34. Alva G, Grossberg GT, Schmitt FA, Meng X, Olin JT: Efficacy of rivastigmine transdermal patch on activities of daily living: item responder analyses. Int J Geriatr Psychiatry 2011, 26:356-363.

35. Atchison TB, Massman PJ, Doody RS: Baseline cognitive function predicts rate of decline in basic-care abilities of individuals with dementia of the Alzheimer's type. Arch Clin Neuropsychol 2007, 22:99-107.

36. Molinuevo JL, Berthier ML, Rami L: Donepezil provides greater benefits in mild compared to moderate Alzheimer's disease: implications for early diagnosis and treatment. Arch Gerontol Geriatr 2011, 52:18-22.

37. Brown PJ, Devanand DP, Liu X, Caccappolo E: Alzheimer's disease neuroimaging I: functional impairment in elderly patients with mild cognitive impairment and mild Alzheimer disease. Arch Gen Psychiatry 2011, 68:617-626.

38. Wattmo C, Wallin AK, Londos E, Minthon L: Predictors of long-term cognitive outcome in Alzheimer's disease. Alzheimers Res Ther 2011, 3:23.

39. Wilkosz PA, Seltman HJ, Devlin B, Weamer EA, Lopez OL, DeKosky ST, Sweet RA: Trajectories of cognitive decline in Alzheimer's disease. Int Psychogeriatr 2010, 22:281-290.

40. Mungas D, Reed BR, Ellis WG, Jagust WJ: The effects of age on rate of progression of Alzheimer disease and dementia with associated cerebrovascular disease. Arch Neurol 2001, 58:1243-1247.

41. Musicco M, Palmer K, Salamone G, Lupo F, Perri R, Mosti S, Spalletta G, Di Iulio F, Pettenati C, Cravello L, Caltagirone C: Predictors of progression of cognitive decline in Alzheimer's disease: the role of vascular and sociodemographic factors. J Neurol 2009, 256:1288-1295.

42. Doody RS, Pavlik V, Massman P, Rountree S, Darby E, Chan W: Predicting progression of Alzheimer's disease. Alzheimers Res Ther 2010, 2:2.

43. Unverzagt FW, Hui SL, Farlow MR, Hall KS, Hendrie HC: Cognitive decline and education in mild dementia. Neurology 1998, 50:181-185.

44. Wilson RS, Li Y, Aggarwal NT, Barnes LL, McCann JJ, Gilley DW, Evans DA: Education and the course of cognitive decline in Alzheimer disease. Neurology 2004, 63:1198-1202.

45. Amieva H, Jacqmin-Gadda H, Orgogozo JM, Le Carret N, Helmer C, Letenneur L, Barberger-Gateau P, Fabrigoule C, Dartigues JF: The 9 year cognitive decline before dementia of the Alzheimer type: a prospective population-based study. Brain 2005, 128:1093-1101.

46. Cosentino S, Scarmeas N, Helzner E, Glymour MM, Brandt J, Albert M, Blacker D, Stern Y: APOE epsilon 4 allele predicts faster cognitive decline in mild Alzheimer disease. Neurology 2008, 70:1842-1849.

47. Craft S, Teri L, Edland SD, Kukull WA, Schellenberg G, McCormick WC Bowen JD, Larson EB: Accelerated decline in apolipoprotein E-epsilon4 homozygotes with Alzheimer's disease. Neurology 1998, 51:149-153.

48. Murphy GM Jr, Taylor J, Kraemer HC, Yesavage J, Tinklenberg JR: No association between apolipoprotein E epsilon 4 allele and rate of decline in Alzheimer's disease. Am J Psychiatry 1997, 154:603-608.

49. Kleiman T, Zdanys K, Black B, Rightmer T, Grey M, Garman K, Macavoy M, Gelernter J, Van Dyck C: Apolipoprotein E epsilon4 allele is unrelated to cognitive or functional decline in Alzheimer's disease: retrospective and prospective analysis. Dement Geriatr Cogn Disord 2006, 22:73-82.

50. Hoyt BD, Massman PJ, Schatschneider C, Cooke N, Doody RS: Individual growth curve analysis of APOE epsilon 4-associated cognitive decline in Alzheimer disease. Arch Neurol 2005, 62:454-459.

51. Salloway S, Sperling R, Honig L, Porsteinsson A, Sabbagh M, Liu E, Yuen E, Lull J, Miloslavsky M, Reichert M, Ketter N, Grundman M, Black R, Brashear R: A randomized, double-blind, placebo-controlled clinical trial of intravenous bapineuzumab in patients with mild to moderate Alzheimer's disease who are apolipoprotein E $\varepsilon 4$ non-carriers. In 16th Congress of the European Federation of Neurological Societies. Stockholm, Sweden; 2012. http://www2. kenes.com/efns/info/Documents/Salloway_Bapineuzumab\%20IV\%20Study\% 20301_EFNS\%20Presentation\%20Slides_9-11-2012.pdf Accessed: June 14, 2013.

52. Galimberti D, Ghezzi L, Scarpini E: Immunotherapy against amyloid pathology in Alzheimer's disease. J Neurol Sci 2013. Epub ahead of print.

53. Locascio JJ, Atri A: An overview of longitudinal data analysis methods for neurological research. Dement Geriatr Cogn Dis Extra 2011, 1:330-357.

54. Ritchie CW, Ames D, Clayton T, Lai R: Metaanalysis of randomized trials of the efficacy and safety of donepezil, galantamine, and rivastigmine for the treatment of Alzheimer disease. Am J Geriatr Psychiatry 2004, 12:358-369.

55. Geldmacher DS, Provenzano G, McRae T, Mastey V, leni JR: Donepezil is associated with delayed nursing home placement in patients with Alzheimer's disease. J Am Geriatr Soc 2003, 51:937-944.

56. Wattmo C, Paulsson E, Minthon L, Londos E: A longitudinal study of risk factors for community-based home help services in Alzheimer's disease: the influence of cholinesterase inhibitor therapy. Clin Interv Aging 2013, 8:329-339.

57. Wattmo C, Jedenius E, Blennow K, Wallin AK: Dose and plasma concentration of galantamine in Alzheimer's disease-clinical application. Alzheimers Res Ther 2013, 5:2.

\subsection{6/alzrt210}

Cite this article as: Wattmo et al:: Progression of mild Alzheimer's disease: knowledge and prediction models required for future treatment strategies. Alzheimer's Research \& Therapy 2013, 5:44

\section{Submit your next manuscript to BioMed Central and take full advantage of:}

- Convenient online submission

- Thorough peer review

- No space constraints or color figure charges

- Immediate publication on acceptance

- Inclusion in PubMed, CAS, Scopus and Google Scholar

- Research which is freely available for redistribution 